\title{
Target Anatomic Site Condition Code
}

National Cancer Institute

\section{Source}

National Cancer Institute. Target Anatomic Site Condition Code. NCI Thesaurus. Code C93691.

A coded value specifying the state of the target anatomic site. 